\title{
Geometrical models for cardiac MRI in rodents: comparison of quantification of left ventricular volumes and function by various geometrical models with a full-volume MRI data set in rodents.
}

Citation for published version (APA):

van de Weijer, T., van Ewijk, P. A., Zandbergen, H. R., Slenter, J. M., Kessels, A. G., Wildberger, J. E., Hesselink, M. K. C., Schrauwen, P., Schrauwen-Hinderling, V. B., \& Kooi, M. E. (2012). Geometrical models for cardiac MRI in rodents: comparison of quantification of left ventricular volumes and function by various geometrical models with a full-volume MRI data set in rodents. American Journal of Physiologyheart and Circulatory Physiology, 302(3), H709-H715. https://doi.org/10.1152/ajpheart.00710.2011

Document status and date:

Published: 01/02/2012

DOI:

10.1152/ajpheart.00710.2011

Document Version:

Publisher's PDF, also known as Version of record

Document license:

Taverne

Please check the document version of this publication:

- A submitted manuscript is the version of the article upon submission and before peer-review. There can be important differences between the submitted version and the official published version of record. People interested in the research are advised to contact the author for the final version of the publication, or visit the DOI to the publisher's website.

- The final author version and the galley proof are versions of the publication after peer review.

- The final published version features the final layout of the paper including the volume, issue and page numbers.

Link to publication

\footnotetext{
General rights rights.

- You may freely distribute the URL identifying the publication in the public portal. please follow below link for the End User Agreement:

www.umlib.nl/taverne-license

Take down policy

If you believe that this document breaches copyright please contact us at:

repository@maastrichtuniversity.nl

providing details and we will investigate your claim.
}

Copyright and moral rights for the publications made accessible in the public portal are retained by the authors and/or other copyright owners and it is a condition of accessing publications that users recognise and abide by the legal requirements associated with these

- Users may download and print one copy of any publication from the public portal for the purpose of private study or research.

- You may not further distribute the material or use it for any profit-making activity or commercial gain

If the publication is distributed under the terms of Article 25fa of the Dutch Copyright Act, indicated by the "Taverne" license above,

Download date: 26 Apr. 2023 


\title{
Geometrical models for cardiac MRI in rodents: comparison of quantification of left ventricular volumes and function by various geometrical models with a
}

\section{full-volume MRI data set in rodents}

\author{
Tineke van de Weijer, ${ }^{1,5}$ Petronella A. van Ewijk, ${ }^{1,5}$ H. Reinier Zandbergen, ${ }^{6}$ Jos M. Slenter, ${ }^{3,6}$ \\ Alfons G. Kessels, ${ }^{4}$ Joachim E. Wildberger, ${ }^{3,6}$ Matthijs K. C. Hesselink, ${ }^{2,5}$ Patrick Schrauwen, ${ }^{1,5}$ \\ Vera B. Schrauwen-Hinderling, ${ }^{3,5}$ and Marianne Eline Kooi ${ }^{3,5,6}$ \\ Departments of ${ }^{1}$ Human Biology, ${ }^{2}$ Human Movement Sciences, ${ }^{3}$ Radiology and ${ }^{4}$ Clinical Epidemiology, ${ }^{5}$ Nutrim, School for \\ Nutrition, Toxicology and Metabolism, ${ }^{6}$ Cardiovascular Research Institute Maastricht, Maastricht University Medical Centre, \\ The Netherlands
}

Submitted 18 July 2011; accepted in final form 14 November 2011

van de Weijer T, van Ewijk PA, Zandbergen HR, Slenter JM, Kessels AG, Wildberger JE, Hesselink MK, Schrauwen P, SchrauwenHinderling VB, Kooi ME. Geometrical models for cardiac MRI in rodents: comparison of quantification of left ventricular volumes and function by various geometrical models with a full-volume MRI data set in rodents. Am J Physiol Heart Circ Physiol 302: H709-H715, 2012. First published November 18, 2011; doi:10.1152/ajpheart.00710.2011.— MRI has been proven to be an accurate method for noninvasive assessment of cardiac function. One of the current limitations of cardiac MRI is that it is time consuming. Therefore, various geometrical models are used, which can reduce scan and postprocessing time. It is unclear how appropriate their use is in rodents. Left ventricular (LV) volumes and ejection fraction (EF) were quantified based on 7.0 Tesla cine-MRI in 12 wild-type (WT) mice, 12 adipose triglyceride lipase knockout $\left(\mathrm{ATGL}^{-1-}\right.$ ) mice (model of impaired cardiac function), and 11 rats in which we induced cardiac ischemia. The LV volumes and function were either assessed with parallel short-axis slices covering the full volume of the left ventricle (FV, gold standard) or with various geometrical models [modified Simpson rule (SR), biplane ellipsoid (BP), hemisphere cylinder (HC), single-plane ellipsoid (SP), and modified Teichholz Formula (TF)]. Reproducibility of the different models was tested and results were correlated with the gold standard (FV). All models and the FV data set provided reproducible results for the $\mathrm{LV}$ volumes and $\mathrm{EF}$, with interclass correlation coefficients $\geq 0.87$. All models significantly over- or underestimated EF, except for SR. Good correlation was found for all volumes and EF for the SR model compared with the FV data set $\left(R^{2}\right.$ ranged between $0.59-0.95$ for all parameters). The $\mathrm{HC}$ model and $\mathrm{BP}$ model also predicted $\mathrm{EF}$ well $\left(R^{2} \geq\right.$ 0.85 ), although proved to be less useful for quantitative analysis. The SP and TF models correlated poorly with the FV data set $\left(R^{2} \geq 0.45\right.$ for $\mathrm{EF}$ and $R^{2} \geq 0.29$ for $\mathrm{EF}$, respectively). For the reduction in acquisition and postprocessing time, only the SR model proved to be a valuable method for calculating LV volumes, stroke volume, and EF.

ejection fraction; left ventricular volume

CARDIOVASCULAR DISEASES STILL are one of the main causes of death in Western countries, and the incidence and prevalence of cardiovascular diseases are still increasing $(28,29)$. Therefore, many studies have focused on the prevention, treatment, and etiology of these diseases. Rodent models of cardiac disease have played a critical role in this area of expertise and hence models to assess rodent cardiac function have become increasingly important over the last decades $(12,24)$. MRI has

Address for reprint requests and other correspondence: M. E. Kooi, Dept. of Radiology, Maastricht Univ. Medical Centre, P.O. Box 5800, 6202 AZ Maastricht, The Netherlands (e-mail: eline.kooi@mumc.nl). been proven to be an accurate method for noninvasive assessment of cardiac function in rodents $(22,23,25)$ and has therefore become an important tool in studies of rodent models of cardiac disease $(7,14)$. With MRI, systolic function can be assessed by calculating the ejection fraction (EF) from sequential multislice short-axis cine-MRI covering the complete volume of the left ventricle (25). However, this requires an acquisition of at least six to eight slices (depending on the size of the heart), which can be quite time consuming, especially in studies requiring high spatial resolution. Also manual or semiautomatic analysis of these slices can demand a substantial amount of time in high-throughput applications (31). Furthermore, it might be desirable to be able to allow quick assessment of the cardiac function, as a secondary parameter, without increasing scan time too much. The acquisition duration is not only demanding in terms of scan time but also prolongs the duration of anesthesia and hence increases stress in the animals under investigation $(5,11)$. In specific cardiovascular compromised genotypes, such as the adipose triglyceride lipase knockout $\left(\mathrm{ATGL}^{-1-}\right)$ mouse, which was used in our studies (10), prolonged anesthesia can in some cases increase mortality rate.

To circumvent this, several studies have implemented geometrical models for assessment of cardiac function in rodents, rather than acquiring multiple parallel slices with multislice cine-MRI to determine the full volume of the left ventricle (4, $8,13,15,18,26,30)$. These models estimate left ventricular (LV) volumes based on single or perpendicular biplane or even triplane slices (6) and therefore allow quick assessment of LV volumes and EF, as they only require acquisition of one up to three instead of six to eight slices for mice. For rats, due to the larger size of the left ventricle, the reduction in number of slices is even larger, i.e., 1-3 instead of 6-10 slices. This would substantially reduce total scan time with 10-30 min for mice and even 20-45 min for rats. A typical total examination time during which the mice and rats are kept under anesthesia for assessment of cardiac function is 40-45 and 45-60 min, respectively. Additionally, acquisition of images required for the geometrical models instead of a full volume data set would reduce the number of slices to be segmented to calculate the LV volumes and EF with a factor of 2-3 for mice and 2-4 for rats, thereby also reducing time spent on the assessment of cardiac function in rodent models of cardiac disease.

Although these models have been compared with ultrasound (4) and have been validated in humans (6), to our knowledge no study has determined which of these geometrical models is 
most accurate in determining cardiac function compared with the gold standard, i.e., cine-MRI of the complete left ventricle by full volume imaging in rodents. Therefore, the aim of the present study was to evaluate reproducibility and validity of these geometrical models in mice compared with the gold standard, cine-MRI of the complete left ventricle. After testing the validity of these geometrical models in wild-type mice with anticipated normal cardiac function, we tested applicability of these models in mice with anticipated cardiac failure and in rats in which we induced myocardial infarction.

\section{METHODS}

Animals. Mice and rats were housed under standard conditions at $25^{\circ} \mathrm{C}$ with a $14: 10$-h light-dark cycle with ad libitum access to water and standard chow diet. The Maastricht University Medical Centre Institutional Ethics Committee on Animal Welfare approved all experiments. Twelve wild-type C57BL/6 mice with anticipated normal cardiac function were imaged for validation of the geometrical models. In addition, we extended the validation to a model of severe cardiac dysfunction by using 12 adipose triglyceride lipase knockout mice $\left(\mathrm{ATGL}^{-1-}\right.$, age $8-12 \mathrm{wk}$ ). ATGL ${ }^{-1-}$ mice were generated on a mixed genetic background (50\% C57BL/6 and 50\% 129/Ola) as previously described (9). The targeted ATGL allele was then backcrossed onto the C57BL/6 background strain for $>10$ generations. Furthermore, myocardial infarction (MI) was induced in 11 male Wistar-rats $(300-500 \mathrm{~g})$ by ligation of the left anterior descending coronary artery using a 6-0 Prolene suture, as described previously $(17,19)$. Subsequently, the rats were scanned between 7 and 21 days post-MI.

Before MRI, mice were anesthetized using 1-2\% isoflurane (Abbott Laboratories, Queensborough, UK) in medical air. Neonatal ECG electrodes (3M, St. Paul, MN) were placed on the paws of the right front leg and left hind leg and connected to an MR compatible small animal monitoring system (SA Instruments, Stony Brook, NY). Animals were placed on a warm waterbed. Respiratory rate was continuously monitored.

MRI protocol. MRI was performed on a 7 Tesla Bruker Biospec 70/30 USR (Bruker Biospin, Ettlingen, Germany) using the BGA12-S mini-imaging gradient (maximum gradient strength: $400 \mathrm{mTm}^{-1}$, slew rate: $5,000 \mathrm{Tm}^{-1} \cdot \mathrm{s}^{-1}$, and linear inductive rise time: $5-95 \%$ on all axis, $80 \mu \mathrm{s}$ ), interfaced to an AVANCE II console. First, a bright blood cine image with 10 cardiac phases was recorded in horizontal 4-chamber view $(4 \mathrm{CH})$ using a retrospectively self-gated protocol (IntraGate, Bruker Biospin; imaging time: 2-4 min, for the mice: $2.56 \times 2.56 \mathrm{~cm}^{2}$ field of view, $164 \times 164$ matrix size; for the rats: $5.0 \times 5.0 \mathrm{~cm}^{2}$ field of view, $128 \times 128$ matrix size see Fig. 1, $I$ and $J$ ). This $4 \mathrm{CH}$ orientation was used to plan a long axis view (LA) perpendicular to the $4 \mathrm{CH}$ view with the same self-gated protocol (see Fig. 1, $A, B, E$, and $F$ ). The orientation was defined as a sagittal plane through the mitral valve and the apex. Perpendicular to this LA and $4 \mathrm{CH}$ view and the septum, a short axis view (SA) was positioned (see Fig. 1, $C, D, G, H, K$, and $L$ ). The slice was planned at half height of the left ventricle, $1-2 \mathrm{~mm}$ below the leaflets of the mitral valve. This image was acquired ECG and respiratory gated, using a bright blood gradient echo sequence with the following parameters for the mice studied: repetition time: $11.6 \mathrm{~ms}$, echo time: $2.5 \mathrm{~ms}$, flip angle: $50^{\circ}$, one slice, 1-mm thickness, eight signal averages, field of view: $25.6 \times$ $25.6 \mathrm{~mm}$, and matrix-size: $164 \times 164$, resulting in an in-plane resolution: $0.16 \times 0.16 \mathrm{~mm}^{2}$ and acquisition time: $\sim 4 \mathrm{~min}$. The SA images of the rats were acquired with the following parameters: repetition time: $7 \mathrm{~ms}$, echo time: $2.8 \mathrm{~ms}$, flip angle: $50^{\circ}$, 1 slice, $1.263-\mathrm{mm}$ thickness, one signal average, field of view: $50 \times 50 \mathrm{~mm}$, and matrix-size: $192 \times 192$, resulting in an in-plane resolution: $0.26 \times 0.26 \mathrm{~mm}^{2}$ and acquisition: time $\sim 5 \mathrm{~min}$. For image analysis of the complete LV volumes, five to nine additional slices were planned parallel to the short axis slice with a slice thickness of $1 \mathrm{~mm}$ in the mice and $1.2 \mathrm{~mm}$ in the rats, without gap between slices. The slices covered the whole left ventricle, from the apex to the base. The images were acquired using the same pulse sequence. The average time for acquiring the images needed to assess EF with a full volume data, using eight slices, is $\sim 50 \mathrm{~min}$.

Image analysis. All images were analyzed in OsiriX (Dicom viewer, version 3.5; Pixmeo, Geneva, Switzerland). The end-diastolic volumes (EDV) and end-systolic volumes (ESV) of the left ventricle were considered the largest and the smallest areas, respectively, of the LV cavity in each slice. For the analysis of cine-MRI, the window width and level were manually adjusted to recognize the internal ventricular morphologic characteristics. For the measurements of LV volumes, the whole LV cavity was selected with semiautomated

Fig. 1. Long axis (LA), 4-chamber view (4CH), and short axis (SA) images of adipose triglyceride lipase knockout mice (ATGL ${ }^{-1-}$ ) and wild-type (WT) mice and a rat model of myocardial infarction. Depicted are the LA-plane images of the WT mice. $A$ : in diastole. $B$ : in systole. $E$ : LA-plane image in diastole of a ATGL $^{-1-}$ mice. $F$ : LA-plane image in a ATGL mice in systole. Here a plane through the mitral valve and the apex was chosen to assess left ventricular (LV) length and volume. $\mathrm{I}: 4 \mathrm{CH}$ view is depicted of a rat heart in diastole. $J$ : $4 \mathrm{CH}$ view of a rat heart in diastole, after myocardial infarction. $C$ and $D$ : SA images are depicted in wild-type (WT) mice. $G$ and $H$ : SA images are depicted of a ATGL ${ }^{-1-}$ mice. $K$ and $L$ : SA images are depicted of a rat heart after myocardial infarction in diastole and systole, respectively. SA view was positioned perpendicular to the LA plane and $4 \mathrm{CH}$ view for the quantification of LV volumes. Furthermore, in these images an impaired systolic contraction and a dilated and thickened ventricular wall is visible in the $\mathrm{ATGL}^{-1-}$ mice (middle), as well as an infracted area in the left ventricle and slight dilatation of the rat heart (bottom).
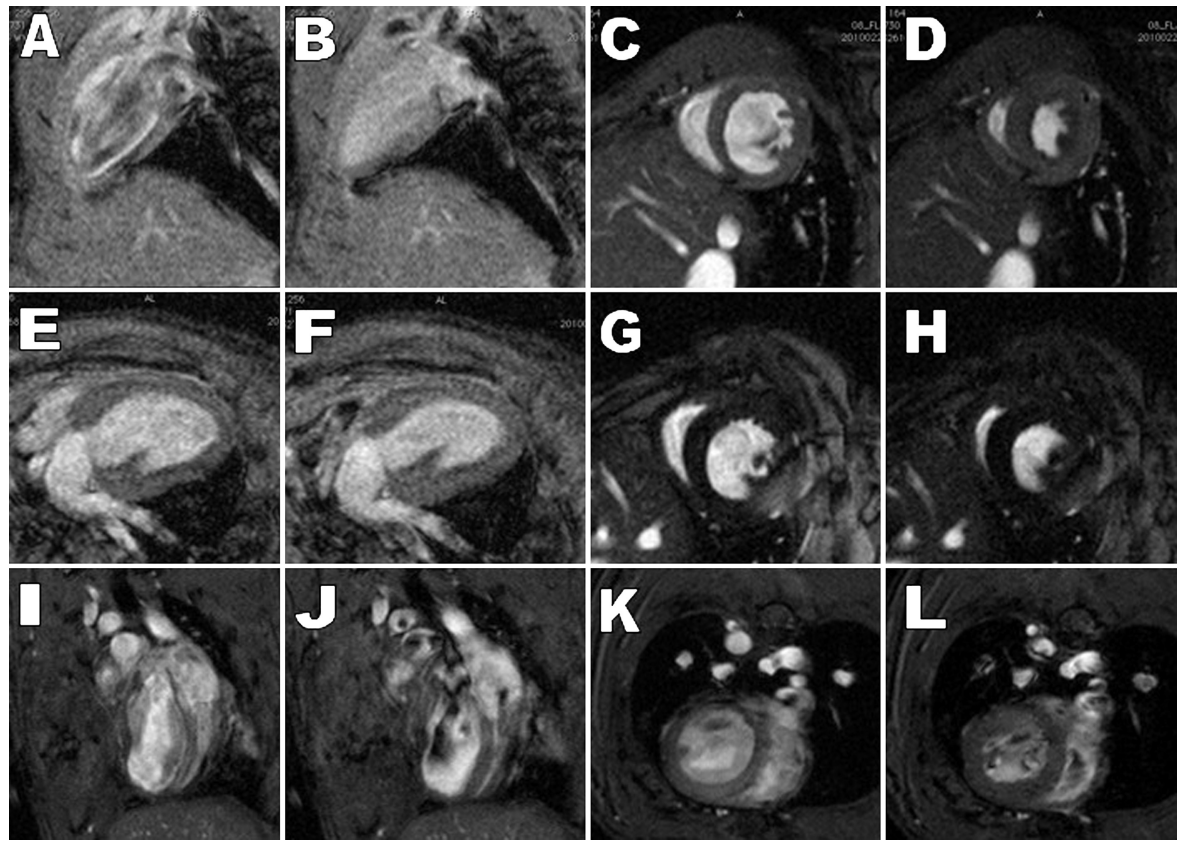
Full volume data set (FV)

$\mathrm{LVV}=\mathrm{S}_{1}+\mathrm{S}_{2}+\mathrm{S}_{3}+\ldots$

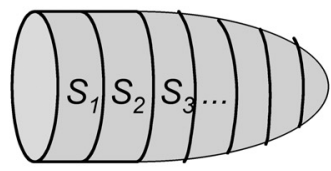

Biplane Ellipsoid model (BP)

$\mathrm{LVV}=\pi / 6 \times L \times\left(4 / \pi \times A_{m} / D\right) \times\left(4 / \pi \times A_{i} / L\right)$

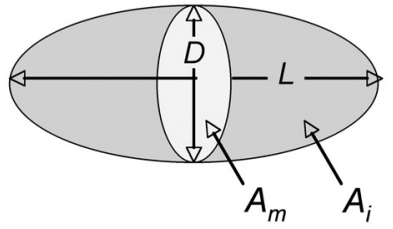

Modified Simpson rule model (SR)

$\mathrm{LVV}=A_{m} \times L / 3+\left(A_{m}+A_{p}\right) / 2 \times L / 3+1 / 3 \times A_{p} \times L / 3$

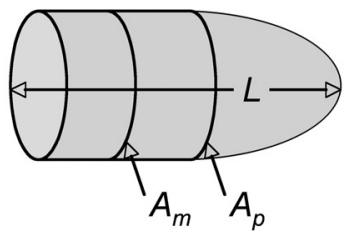

Hemisphere cylinder model (HC)

$\mathrm{LVV}=A_{m} \times L / 2+2 / 3 \times A_{m} \times L / 2=5 / 6 \times A_{m} \times L$

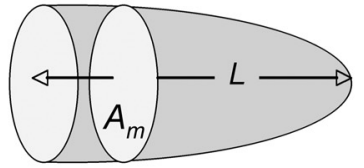

Single-plane Ellipsoid model (SP) $\mathrm{LVV}=\left(8 \times A_{i} \times A_{i}\right) /(3 \pi \times L)=0.85 \times\left(A_{i} \times A_{i}\right) / \mathrm{L}$

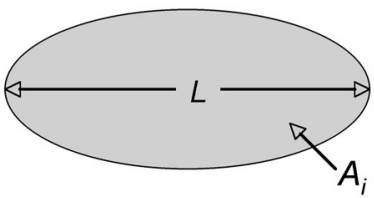

Modified Teichholz Formula (TF)

$\mathrm{LV}=[7 /(2.4+D)] \times D \times D \times D$

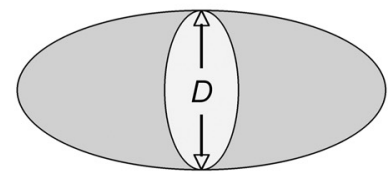

Fig. 2. Algorithms and formula's for calculation of LV volumes with a full volume MRI data set of the complete left ventricle or geometrical models based on a few MRI slices. Top: algorithms for full volume data set and the various geometrical models for the determination of LV volumes and ejection fraction $(\mathrm{EF})$ are presented. $A_{i}$, crosssectional area of LV cavity in the LA plane; $A_{m}$, cross-sectional area of the LV cavity in the SA plane, $\sim 1-2 \mathrm{~mm}$ below the mitral valve; $A_{p}$, cross-sectional area of the LV cavity in the SA plane, approximately at the base of the papillary muscles; $D$, diameter of the LV cavity in the short axis plane, $\sim 1-2$ mm below the mitral valve; $L$, longest length of LV cavity in the LA plane; LVV, LV volumes [end-diastolic volume (EDV) and end-systolic volume (ESV), respectively]; $S 1, S 2, S 3, \ldots, 1-\mathrm{mm}$ SA slices from the apex to the base of the left ventricle. segmentation parameters in OsiriX. The papillary muscle was excluded from the LV volume during analysis. The diameter $(D)$ of the $\mathrm{LV}$ volume on the short axis was measured as the longest distance between the septum and the ventricular wall. Length $(L)$ of the LV on the LA view was defined as the longest distance from the apex to the valves. On average, the time needed to analyze one slice was $3 \mathrm{~min}$.

Data analysis. In all animals, EDV, ESV, stroke volume (SV = EDV - ESV), and EF (EF = SV/EDV) were calculated from the EDV and ESV volumes based on either the multislice short axis cine-images of the complete left ventricle (gold standard) or based on the different geometrical models as described by Dulce et al. 1993 (6). The algorithms and required imaging slices for these models can be found in Fig. 2.

Statistical analysis. Measurements of LV volumes and EF from cine MRI in both the wild type animals and the transgenic ATGL ${ }^{-1-}$ mice are presented as mean values \pm SD. The correlations of $\mathrm{LV}$ volumes and $\mathrm{EF}$, as measured with the various geometric models vs. the full volume data set of the left ventricle (gold standard), were assessed by linear regression analysis. $R^{2}, P$ values, and $95 \%$ individual confidence intervals (also known as prediction intervals) are reported for all regression analysis. Differences in LV volumes and EF between the geometric models and the gold standard were analyzed for statistical significance with a one-way ANOVA. Also, differences in outcome measures between the different genotypes were assessed with a one-way ANOVA for each model separately. $P$ value $<0.05$ was considered statistically significant. Reproducibility was tested by calculating the interclass correlation for two consecutive measurements for all geometrical models and the gold standard in five wild-type mice. For measuring the two consecutive measurements, mice were taken out of the scanner in-between the measurements, where after they were repositioned and all preparatory steps (including shimming and acquisition of scout-images) were repeated.

\section{RESULTS}

Reproducibility. The interclass correlation coefficients for each model for the LV volumes and EF are summarized in Table 1. The interclass correlation coefficient was $>0.85$ for all parameters in each model indicating a good reproducibility for all models.
Validation of $L V$ volumes and EF. The values for $\mathrm{LV}$ volumes and EF in the various animal groups are summarized in Table 2. Only the modified Simpson rule model gave statistically indifferent values for both the LV volumes and the EF compared with the full volume data set for all study groups. All models could pick up the marked differences in LV volumes and EF found between wild-type and transgenic mice $(P<0.05$, one-way ANOVA test, data not shown).

Linear regression analysis. The scatter plots with individual regression lines of the EF quantified by the models vs. the gold standard (quantification based on full volume data set) are provided in Fig. 3. Pearson's correlation coefficients $(r)$, individual $95 \%$ confidence intervals and $R^{2}$ can also be found in Fig. 3. As the modified Simpson rule model was the only model that provided the correct absolute values for EF and LV volumes, we also present the scatter plots of the LV volumes and SV with the full volume data set for this model in Fig. 4 (for mice and rats the data are presented separately).

Table 1. Interclass correlation coefficients of $L V$ volumes and ejection fraction in wild-type animals

\begin{tabular}{lcccr}
\hline \hline & \multicolumn{4}{c}{ Wild-Type Animals-Interclass Correlation Coefficients } \\
\cline { 2 - 5 } & EDV & ESV & SV & EF \\
\hline FV & 0.944 & 0.915 & 0.981 & 0.995 \\
BP & 0.991 & 0.994 & 0.986 & 0.975 \\
SR & 0.995 & 0.981 & 0.986 & 0.955 \\
HC & 0.979 & 0.997 & 0.961 & 0.996 \\
SP & 0.997 & 0.989 & 0.976 & 0.939 \\
TF & 0.983 & 0.893 & 0.887 & 0.866 \\
\end{tabular}

Values were obtained with geometric models and a complete imaging set of the left ventricle (LV) acquired with cine-MRI. Presented are the interclass correlation coefficients of a repeated measurement in 5 mice. EDV and ESV, end-diastolic and end-systolic volume; SV, stroke volume; EF, ejection fraction; FV, full volume data set; BP, biplane ellipsoid model; SR, modified Simpson rule model; HC, hemisphere cylinder model; SP, single plane ellipsoid model; TF, modified Teichholz formula model. 
Table 2. LV volumes and EF

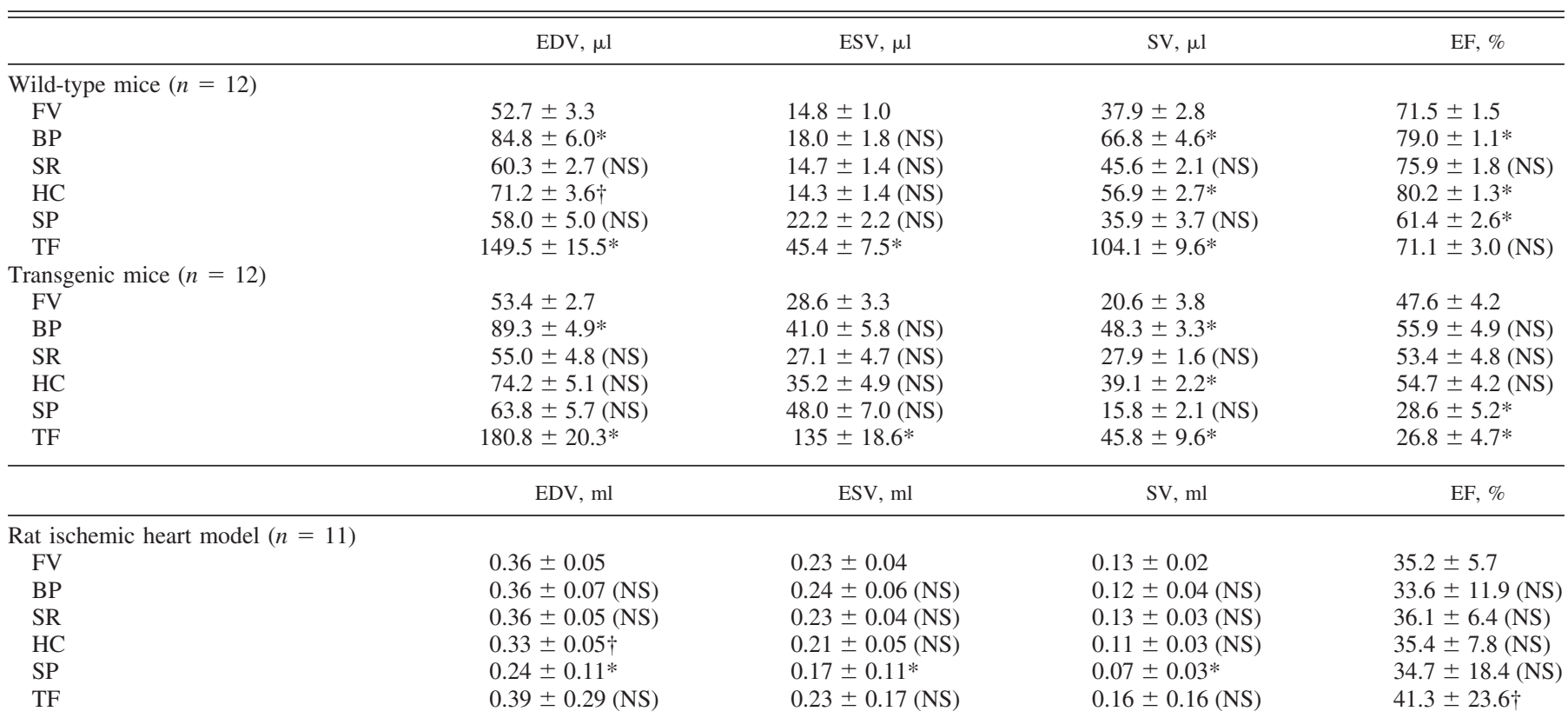

Presented above are the averages and SD of the LV volumes and EF \pm SD per group (wild-type mice, adipose triglyceride lipase knockout mice (ATGL ${ }^{-/-}$)

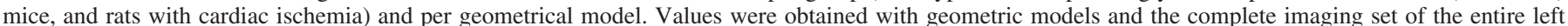
ventricle acquired with cine-MRI. $* P<0.05 ; \uparrow P<0.10$; NS, not significant, when compared with the gold standard (FV).

Although all correlations were significant, only the hemisphere cylinder model, the modified Simpson rule model and the biplane ellipsoid model showed a linear regression with a Pearson's correlation coefficient for EF $>0.85$. The other two models showed a poor correlation with correlation coefficients $<0.7$ and $R^{2}$ values $<0.45$. The $95 \%$ confidence interval was smallest for the modified Simpson rule model, as the $R^{2}$ and $r$ values were the highest for this model $\left(R^{2}=0.937, r=0.968\right.$, and $P<0.001$ ). The $\mathrm{LV}$ volumes and $\mathrm{SV}$, as calculated with the modified Simpson rule model, correlated with the full volume data set both in the mouse models as well as in the rat model. However, it should be noticed that the correlations were stronger for the rat model. The $R^{2}$ values ranged between $0.59-0.95$ with $P$ values $<0.01$ for all correlations (also see Fig. 4).

\section{DISCUSSION}

In this study, we aimed to assess the validity of common geometrical models compared with the gold standard, a full volume data set, for quantification of LV volumes and EF with cine-MRI in rodents. We showed that the reproducibility of all models was good, with higher variations in the Teichholz formula model. When the models were compared with the full volume data set, only the modified Simpson rule model showed no significant differences with the gold standard for all the calculated parameters. The values found for the LV volumes, SV, and EF with the modified Simpson rule model correlated well with the full volume data set (gold standard). Also the EF found with the hemisphere cylinder and biplane ellipsoid model showed high correlation coefficients with the full volume data set. The two remaining models were poor predictors of EF.

Although these findings are new for MRI applications, previous research using other imaging modalities already pointed in this direction. For instance, it has been shown that the Teichholz formula model does not give comparable results in MRI compared with ultrasound (4). These results also did not correlate with values found with the modified Simpson rule model in this study either (4). The discrepancy in absolute values compared with the gold standard for all models except the modified Simpson rule points out that care should be taken when cardiac function is compared between studies using different methodology.

By using the modified Simpson rule, one needs to acquire and assess only three imaging planes, thereby reducing total examination time by $10-45$ min compared with total examination time including positioning of the animal of 30-60 min in the present study. In addition, segmentation time is reduced by two to threefold (depending on the animal species used). The modified Simpson rule model is the only model that divides the heart into three different compartments, based on three imaging planes. This may explain why it is more accurate in estimating the LV volumes, and therefore it might also be more sensitive for nonsymmetrical pathologies (like myocardial infarction, for instance). The other models are based on only one (modified Teichholz formula and single plane ellipsoid model) or two (Hemisphere and biplane ellipsoid models) imaging planes. The most simplified models, using only one plane, showed indeed the weakest correlations, whereas the two plane models did better. Although the EF as determined by these two plane models correlated well with the EF calculated from the full volume data set, they significantly over- or underestimated the real volumes of the left ventricle. Therefore, only the modified Simpson rule can be applied in rodent studies of cardiac disease.

For high throughput studies, parallel imaging or simultaneous scanning of multiple animals might by used as an alternative to reduce scan time. These methods will, however, not lead to a 
A
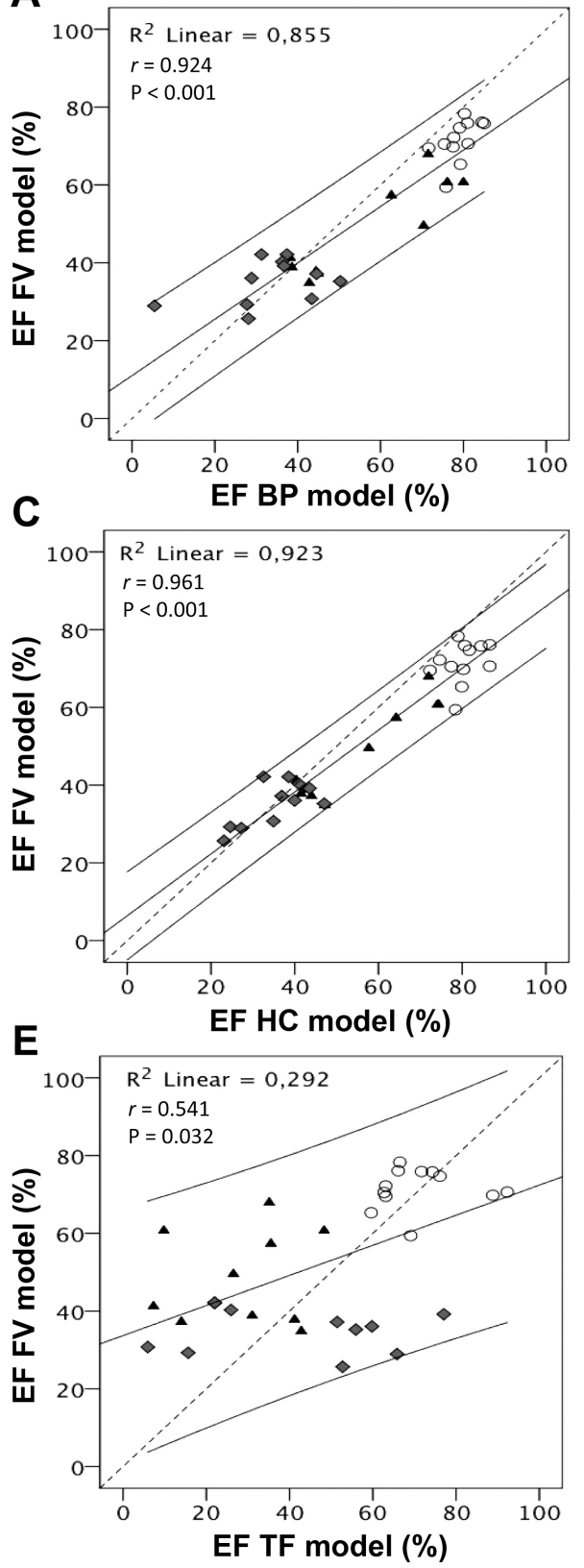

B

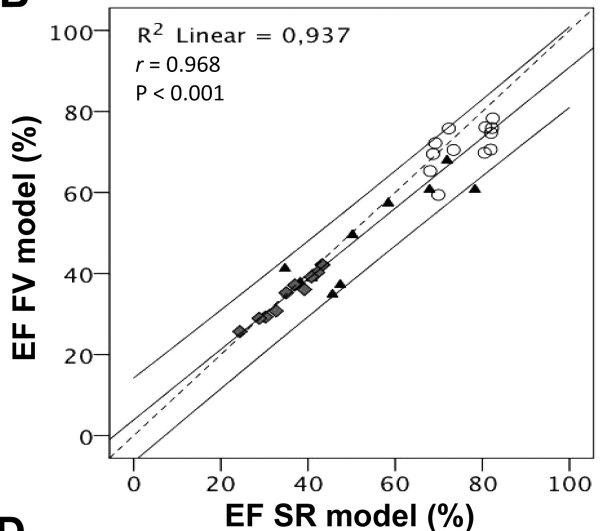

D

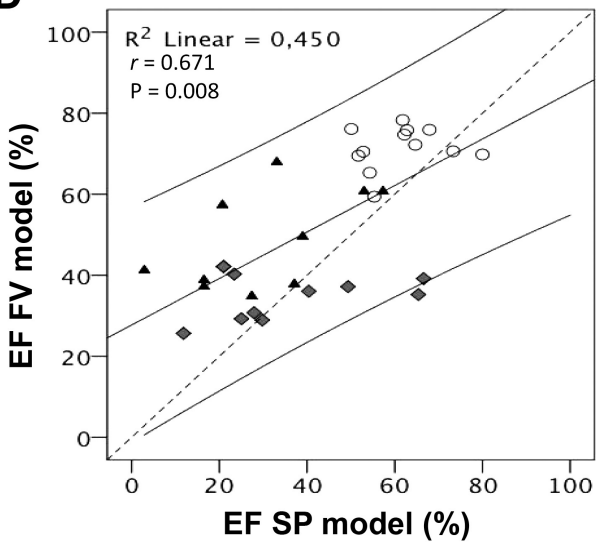

Wild type mice

$\triangle$ ATGL-/-mice

$\checkmark$ Ischemic rat model
Fig. 3. Scatter plots of EF. Scatter plots of EFs of the various models vs. full volume data set for $A$. B: biplane ellipsoid model. $C$ : modified Simpson rule model. $C$ : hemisphere cylinder model. $D$ : single plane ellipsoid model. $E$ : modified Teichholz Formula. In all scatter plots, the regression line is given with a $95 \%$ confidence interval. $R$ squares and Pearson correlation coefficients (with according $P$ values) can also be found in the graph for each fit. reduction in segmentation time. Scanning multiple animals simultaneously is still a quite new technique, which requires specific system requirements (1-3). Parallel imaging leads to a reduction of the signal-to-noise ratio and therefore may not always be appropriate $(16,20,21,27)$. The Simpson rule model could be a good alternative, and combining parallel imaging with the Simpson rule model will even further increase the throughput.

One of the limitations of this study is that the mouse model of transient cardiac disease, namely the $\mathrm{ATGL}^{-1-}$ as a model for cardiomyopathy, is quite a rare model. Nonetheless, we choose to use this model as their cardiac function is severely impaired and the progression of their disease is rather extreme (9), which introduces variation in the main outcome parameters as can be found in Table 2. This variation is not due to a poor reproducibility in this specific group, rather it is due to variation of the disease stage as cardiac function drastically drops with age. A greater variation in the outcome parameters gives a larger spread in the data and makes these data more suited for linear regression analysis. Therefore, this model was ideal for looking at correlations in EF. In addition to the ATGL ${ }^{-1-}$ mice, we also included wild-type mice and rats with myocardial infarction in the present study, since these are more commonly used.

Introducing the rat model of myocardial infarction in this study not only introduced a more common model of cardiac disease but also increased the number of animals for linear regression analysis of EF. One drawback might be that we did handle two different kinds of species in the same analysis. Therefore, we analyzed the correlations between the modified Simpson rule model and full volume data set for the LV volumes and SV for the different animal species separately. The LV volumes seemed to correlate better in the rat model than in the mouse model. The differences in the correlations found are most likely due to the better estima- 

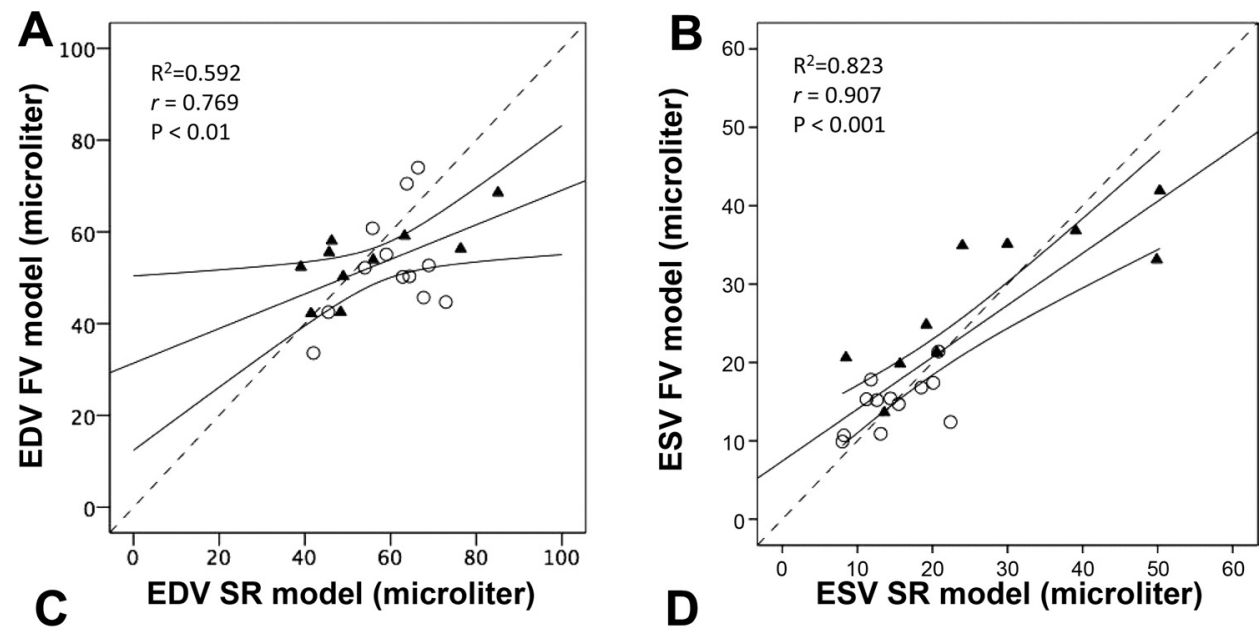

Fig. 4. Scatter plots of LVV for the modified Simpson rule vs. the full volume data set. Scatter plots of LVV and stroke volume for the modified Simpson rule model (SR) vs. full volume data set. A: scatter plot for the $\mathrm{EDV}$ in WT $(\mathrm{O})$ and $\mathrm{ATGL}^{-1-}(\boldsymbol{\Delta})$ mice. $B$ : scatter plot for the ESV in WT and $\mathrm{ATGL}^{-1-}$ mice. $C$ : scatter plot for the stroke volumes in WT and $\mathrm{ATGL}^{-1-}$ mice. $D$ : scatter plot for the EDV in rats with myocardial infarction (MI) ( ). E: scatter plot for the ESV in rats with MI. $F$ : scatter plot for the stroke volumes in rats with MI. In all scatter plots, the regression line is given with a $95 \%$ confidence interval. Dotted line in the graph represents $x=y . R$ squares and Pearson correlation coefficients (with according $P$ values) can also be found in the graph for each fit.
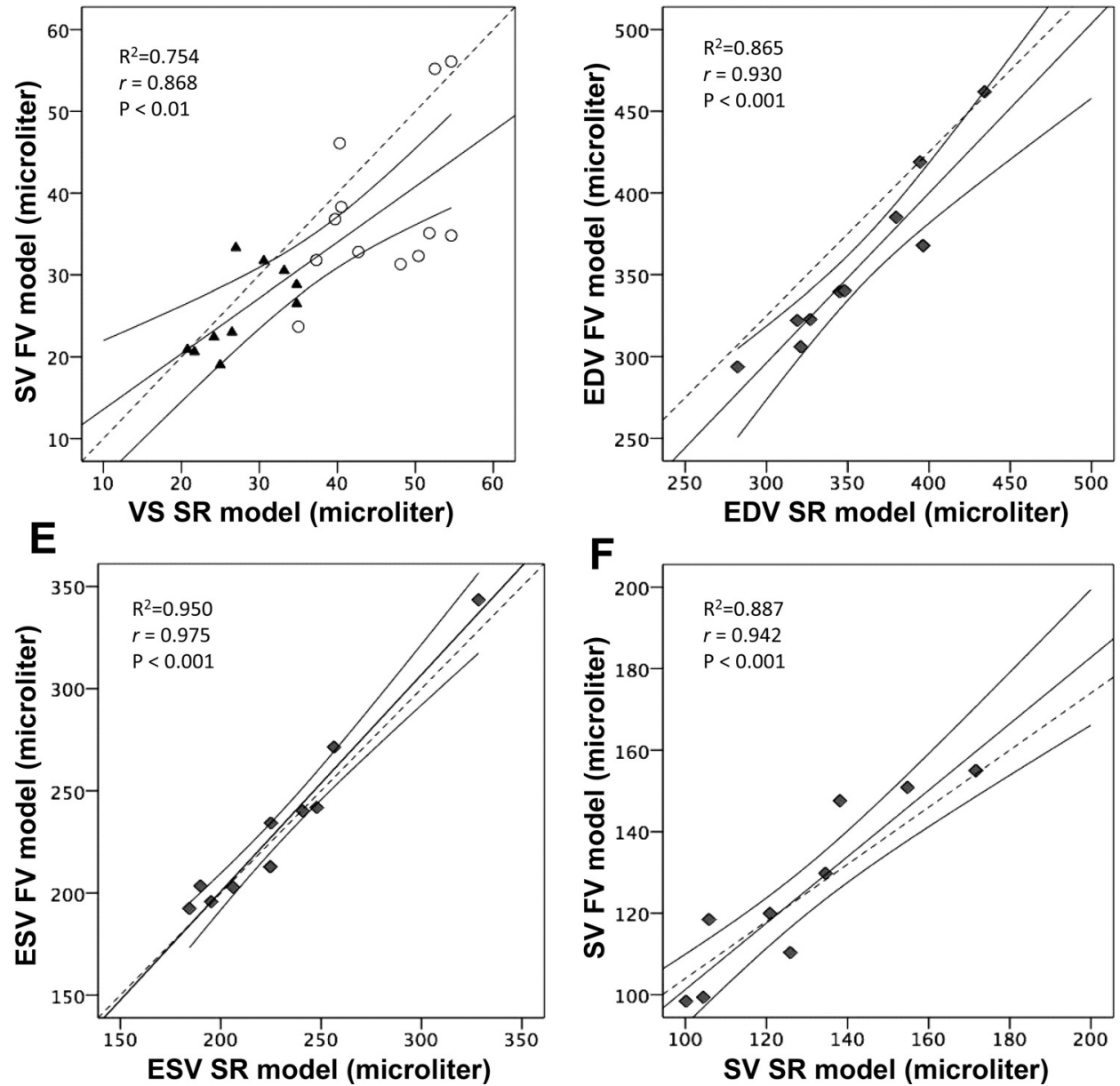

tion of the LV volumes in the segmentation analysis of the rat hearts due to relatively higher resolution of the left ventricle (as the $\mathrm{LV}$ is quite a bit bigger in rats). Also, the spread of the EDV in the rat hearts was greater, resulting in a better spread of the data suitable for regression analysis.

In conclusion, the modified Simpson rule is a good alternative to a full volume data set and reduces scan and postprocessing time. Comparing the absolute values as determined by different geometrical models should be done with caution as they give variable results.

\section{GRANTS}

This work was supported by the Center for Translational Molecular Medicine and the Netherlands Heart Foundation, Dutch Diabetes Research Foundation, and Dutch Kidney Foundation (PREDICCt). V. B. Schrauwen-Hinderling is supported by a VENI grant from the Netherlands Organisation for Scientific Research (NWO).

\section{DISCLOSURES}

No conflicts of interest, financial or otherwise, are declared by the author(s). 


\section{REFERENCES}

1. Bishop J, Feintuch A, Bock NA, Nieman B, Dazai J, Davidson L, Henkelman RM. Retrospective gating for mouse cardiac MRI. Magn Reson Med 55: 472-477, 2006.

2. Bock NA, Konyer NB, Henkelman RM. Multiple-mouse MRI. Magn Reson Med 49: 158-167, 2003.

3. Bock NA, Nieman BJ, Bishop JB, Henkelman MR. In vivo multiplemouse MRI at 7 Tesla. Magn Reson Med 54: 1311-1316, 2005.

4. Bunck AC, Engelen MA, Schnackenburg B, Furkert J, Bremer C, Heindel W, Stypmann J, Maintz D. Feasibility of functional cardiac MR imaging in mice using a clinical 3 Tesla whole body scanner. Invest Radiol 44: 749-756, 2009.

5. Cottrell JE. We care, therefore we are: anesthesia-related morbidity and mortality: the 46th Rovenstine Lecture. Anesthesiology 109: 377-388, 2008.

6. Dulce MC, Mostbeck GH, Friese KK, Caputo GR, Higgins CB. Quantification of the left ventricular volumes and function with cine MR imaging: comparison of geometric models with three-dimensional data. Radiology 188: 371-376, 1993.

7. Epstein FH. MR in mouse models of cardiac disease. NMR Biomed 20: 238-255, 2007.

8. Franco F, Dubois SK, Peshock RM, Shohet RV. Magnetic resonance imaging accurately estimates LV mass in a transgenic mouse model of cardiac hypertrophy. Am J Physiol Heart Circ Physiol 274: H679-H683, 1998.

9. Haemmerle G, Lass A, Zimmermann R, Gorkiewicz G, Meyer C, Rozman J, Heldmaier G, Maier R, Theussl C, Eder S, Kratky D, Wagner EF, Klingenspor M, Hoefler G, Zechner R. Defective lipolysis and altered energy metabolism in mice lacking adipose triglyceride lipase. Science 312: 734-737, 2006.

10. Haemmerle G, Moustafa T, Woelkart G, Buttner S, Schmidt A, van de Weijer T, Hesselink M, Jaeger D, Kienesberger PC, Zierler $\mathbf{K}$ Schreiber R, Eichmann T, Kolb D, Kotzbeck P, Schweiger M, Kumari M, Eder S, Schoiswohl G, Wongsiriroj N, Pollak NM, Radner FP, Preiss-Landl K, Kolbe T, Rulicke T, Pieske B, Trauner M, Lass A, Zimmermann R, Hoefler G, Cinti S, Kershaw EE, Schrauwen P, Madeo F, Mayer B, Zechner R. ATGL-mediated fat catabolism regulates cardiac mitochondrial function via PPAR-alpha and PGC-1. Nat Med 17: 1076-1085.

11. Hanusch C, Hoeger S, Beck GC. Anaesthesia of small rodents during magnetic resonance imaging. Methods 43: 68-78, 2007.

12. Hasenfuss G. Animal models of human cardiovascular disease, heart failure and hypertrophy. Cardiovasc Res 39: 60-76, 1998.

13. Heijman E, Aben JP, Penners C, Niessen P, Guillaume R, van Eys G, Nicolay K, Strijkers GJ. Evaluation of manual and automatic segmentation of the mouse heart from CINE MR images. J Magn Reson Imaging 27: 86-93, 2008.

14. Hiller KH, Waller C, Haase A, Jakob PM. Magnetic resonance of mouse models of cardiac disease. Handb Exp Pharmacol: 245-257, 2008.

15. Iltis I, Kober F, Dalmasso C, Cozzone PJ, Bernard M. Noninvasive characterization of myocardial blood flow in diabetic, hypertensive, and diabetic-hypertensive rats using spin-labeling MRI. Microcirculation 12: 607-614, 2005.
16. Jakob PM, Griswold MA, Edelman RR, Manning WJ, Sodickson DK. Accelerated cardiac imaging using the SMASH technique. $J$ Cardiovasc Magn Reson 1: 153-157, 1999.

17. Kenis H, Zandbergen HR, Hofstra L, Petrov AD, Dumont EA, Blankenberg FD, Haider N, Bitsch N, Gijbels M, Verjans JW, Narula N, Narula J, Reutelingsperger CP. Annexin A5 uptake in ischemic myocardium: demonstration of reversible phosphatidylserine externalization and feasibility of radionuclide imaging. J Nucl Med 51: 259-267, 2010.

18. Oostendorp M, Douma K, Wagenaar A, Slenter JM, Hackeng TM, van Zandvoort MA, Post MJ, Backes WH. Molecular magnetic resonance imaging of myocardial angiogenesis after acute myocardial infarction. Circulation 121: 775-783, 2010.

19. Palojoki E, Saraste A, Eriksson A, Pulkki K, Kallajoki M, VoipioPulkki LM, Tikkanen I. Cardiomyocyte apoptosis and ventricular remodeling after myocardial infarction in rats. Am J Physiol Heart Circ Physiol 280: H2726-H2731, 2001.

20. Pruessmann KP, Weiger M, Scheidegger MB, Boesiger P. SENSE: sensitivity encoding for fast MRI. Magn Reson Med 42: 952-962, 1999.

21. Roemer PB, Edelstein WA, Hayes CE, Souza SP, Mueller OM. The NMR phased array. Magn Reson Med 16: 192-225, 1990.

22. Ross AJ, Yang Z, Berr SS, Gilson WD, Petersen WC, Oshinski JN French BA. Serial MRI evaluation of cardiac structure and function in mice after reperfused myocardial infarction. Magn Reson Med 47: 1158 1168, 2002.

23. Ruff J, Wiesmann F, Hiller KH, Voll S, von Kienlin M, Bauer WR, Rommel E, Neubauer S, Haase A. Magnetic resonance microimaging for noninvasive quantification of myocardial function and mass in the mouse. Magn Reson Med 40: 43-48, 1998.

24. Russell JC, Proctor SD. Small animal models of cardiovascular disease: tools for the study of the roles of metabolic syndrome, dyslipidemia, and atherosclerosis. Cardiovasc Pathol 15: 318-330, 2006.

25. Schneider JE, Cassidy PJ, Lygate C, Tyler DJ, Wiesmann F, Grieve SM, Hulbert K, Clarke K, Neubauer S. Fast, high-resolution in vivo cine magnetic resonance imaging in normal and failing mouse hearts on a vertical 11.7 T system. J Magn Reson Imaging 18: 691-701, 2003.

26. Shohet RV, Kisanuki YY, Zhao XS, Siddiquee Z, Franco F, Yanagisawa M. Mice with cardiomyocyte-specific disruption of the endothelin-1 gene are resistant to hyperthyroid cardiac hypertrophy. Proc Natl Acad Sci USA 101: 2088-2093, 2004.

27. Sodickson DK. Tailored SMASH image reconstructions for robust in vivo parallel MR imaging. Magn Reson Med 44: 243-251, 2000.

28. Uemura K, Pisa $\mathbf{Z}$. Recent trends in cardiovascular disease mortality in 27 industrialized countries. World Health Stat Q 38: 142-162, 1985.

29. Uemura K, Pisa Z. Trends in cardiovascular disease mortality in industrialized countries since 1950. World Health Stat $Q$ 41: 155-178, 1988

30. Wiesmann F, Frydrychowicz A, Rautenberg J, Illinger R, Rommel E, Haase A, Neubauer S. Analysis of right ventricular function in healthy mice and a murine model of heart failure by in vivo MRI. Am J Physiol Heart Circ Physiol 283: H1065-H1071, 2002.

31. Young AA, Barnes H, Davison D, Neubauer S, Schneider JE. Fast left ventricular mass and volume assessment in mice with three-dimensional guide-point modeling. J Magn Reson Imaging 30: 514-520, 2009. 